\title{
Benign meningiomas (WHO Grade I) with atypical histological features: correlation of histopathological features with clinical outcomes
}

\author{
Ariel E. Marciscano, MD, ${ }^{1}$ Anat O. Stemmer-Rachamimov, MD, ${ }^{2}$ Andrzej Niemierko, $\mathrm{PhD},{ }^{3}$ \\ Mykol Larvie, MD, PhD, ${ }^{4}$ William T. Curry, MD, ${ }^{5}$ Fred G. Barker II, MD, ${ }^{5}$ Robert L. Martuza, MD, ${ }^{5}$ \\ Declan McGuone, MB, BCh, ${ }^{2}$ Kevin S. Oh, MD, ${ }^{3}$ Jay S. Loeffler, MD, ${ }^{3}$ and Helen A. Shih, MD ${ }^{3}$ \\ 1Department of Radiation Oncology and Molecular Radiation Sciences, Johns Hopkins University, Baltimore, Maryland; and \\ Departments of ${ }^{2}$ Pathology, ${ }^{3}$ Radiation Oncology, ${ }^{4}$ Radiology, and ${ }^{5}$ Neurosurgery, Massachusetts General Hospital, Boston, \\ Massachusetts
}

\begin{abstract}
OBJECTIVE World Health Organization (WHO) Grade I (benign) meningiomas with atypical features may behave more aggressively than similarly graded tumors without atypical features. Here, the prognostic significance of atypical features in benign meningiomas was determined.
\end{abstract}

METHODS Data from patients diagnosed with WHO Grade I benign meningiomas per the 2007 WHO criteria and who underwent surgery between 2002 and 2012 were retrospectively reviewed. Patients were stratified by the absence or presence of 1 to 2 atypical features with review of the clinical and histological factors.

RESULTS A total of 148 patients met the inclusion criteria ( $n=77$ with atypia; $n=71$ without atypia). The median follow-up duration after pathological diagnosis was 37.5 months. Thirty patients had progression/recurrence (P/R) after initial treatment, and $22(73 \%)$ of 30 patients with P/R had 1-2 atypical features. The presence of atypical features was significantly associated with P/R ( $p=0.03)$ and independent of the MIB-1 labeling index. The 1-year and 5-year actuarial rates of $P / R$ were $9.6 \%$ versus $1.4 \%$ and $30.8 \%$ versus $13.8 \%$ for tumors with and without atypical features, respectively. Higher Simpson grade resection (II-IV vs I) was associated with the increased risk of P/R $(p<0.001)$. Stratification of patients into low-risk (Simpson Grade I), intermediate-risk (Simpson Grade II-IV with no atypical features), and high-risk groups (Simpson Grade II-IV with atypical features) was significantly correlated with increased risk of P/R $(p<0.001)$.

CONCLUSIONS Patients with benign meningiomas with atypical features and those undergoing Simpson Grade II-IV resection are at significantly increased risk of $P / R$. Patients with these features may benefit from the consideration of additional surgery and/or radiation therapy.

http://thejns.org/doi/abs/10.3171/2015.1.JNS142228

KEY WORDS atypical; atypia; benign; histopathological; meningioma; Simpson grade; oncology

$\mathrm{M}$ ENINGIOMAS are the most common primary brain tumors, representing approximately $36 \%$ of all primary central nervous system tumors and over half of all nonmalignant primary brain and central nervous system tumors. ${ }^{19}$ World Health Organization (WHO) Grade I or benign meningiomas are generally regarded to have indolent behavior. However, patients with WHO Grade II (atypical) and WHO Grade III (anaplastic) meningiomas have worse prognosis and are at increased risk of recurrence even with definitive treatment., ${ }^{9}, 1,13,21$

There is a paucity of randomized prospective data to guide the management of meningiomas. Most clinical decision making is driven by retrospective evidence, institutional preference, and practitioner experience. This is further complicated by the reclassification of the WHO criteria for meningiomas, which integrated histopathological features and led to changes in the grading of a substantial proportion of tumors. ${ }^{5,23,25,32}$ As a result, interpreting data from retrospective studies utilizing older WHO criteria may not be entirely applicable. There remain many uncertainties regarding the optimal therapies for benign and aggressive subtypes of meningiomas. ${ }^{2,22,24,29}$

ABBREVIATIONS $\mathrm{Cl}=$ confidence interval; $\mathrm{HR}=$ hazard ratio; $\mathrm{N}: \mathrm{C}=$ nuclear:cytoplasmic; $\mathrm{NF2}$ = neurofibromatosis Type 2; $\mathrm{P} / \mathrm{R}=$ progression/recurrence; $\mathrm{RT}=$ radiotherapy; STR = subtotal resection; $\mathrm{WHO}=$ World Health Organization .

SUBMITTED September 25, 2014. ACCEPTED January 22, 2015.

INCLUDE WHEN CITING Published online August 14, 2015; DOI: 10.3171/2015.1.JNS142228. 
The WHO classification has evolved to reflect the strong link between histopathological appearance and risk of progression/recurrence (P/R). The 1979 classification acknowledged that anaplastic meningiomas were a distinct, aggressive subtype of meningioma with a worse prognosis. In 1993, the WHO classification schema recognized the existence of an intermediate group of atypical meningiomas with a distinct risk of recurrence in comparison to their benign and anaplastic counterparts. Arguably, the most important revision to the WHO classification came in 2000, which introduced histopathology as a methodology to distinguish tumor grades and prognosticate P/R risk. ${ }^{14,31}$ Per the current 2007 guidelines, WHO Grade I meningiomas have fewer than 4 mitotic cells per $10 \mathrm{hpf}$ and fewer than 3 atypical features: increased cellularity, necrosis, prominent nucleoli, sheeting, and a high nuclear:cytoplasmic $(\mathrm{N}: \mathrm{C})$ ratio. ${ }^{15}$

According to the current WHO grading system, categorization as a benign meningioma permits the presence of up to 2 atypical features. The significance of atypical features in benign meningiomas is not well understood and whether their presence prognosticates the risk of $P / R$ is currently unknown. Other histopathological features have been associated with risk of recurrence. In particular, the MIB-1 index has been used as a marker of recurrence risk and studies have reported that increased MIB-1 index may be prognostic of recurrence among benign meningiomas after initial resection..$^{10,16,18}$ The primary objective of this study was to determine the prognostic significance of the atypical features in benign meningiomas, independent of mitoses and elevated MIB-1 index, and if these "gray zone" benign tumors are at a clinically significant increased risk of $\mathrm{P} / \mathrm{R}$.

Adjuvant radiotherapy (RT) has been shown to improve local control, ${ }^{1,4}$ disease-free survival, ${ }^{7,8}$ and overall survival $^{11}$ among atypical and anaplastic meningiomas, particularly after subtotal resection (STR).$^{17}$ However, the role of adjuvant RT among benign meningiomas remains controversial. Often, surgery alone with long-term surveillance is considered an appropriate definitive therapy, and salvage RT and/or re-resection may be offered if P/R occurs. After initial definitive treatment, a proportion of benign meningiomas will recur, supporting the existence of a subset of tumors that behave more aggressively. A secondary study aim was to identify other tumor-intrinsic or treatment-related factors that predispose benign meningiomas to $\mathrm{P} / \mathrm{R}$. The ability to identify these factors at the time of diagnosis or surgery may help guide clinical decisions regarding further treatment.

\section{Methods \\ Patient Selection}

We retrospectively reviewed data obtained from all patients who were consecutively treated at our institution between 2002 and 2012 with histologically confirmed, intracranial benign meningiomas without brain invasion. Eligibility criteria included a diagnosis, according to the 2007 classification, of WHO Grade I meningioma. Patients with 1-2 histopathological features of atypia $(n=77)$ (increased cellularity, sheeting, prominent nucleoli, necrosis, or high $\mathrm{N}: \mathrm{C}$ ratio) were grouped into a benign meningioma with atypia cohort. From the same time period, a benign meningioma without atypia cohort $(n=71)$ was identified as the comparison group. Patients with less than 1 year of clinical and radiological follow-up at our institution were excluded. This study was conducted with institutional review board approval.

\section{Assessed Parameters}

For patients undergoing initial observation, age at diagnosis was defined as the age at time of the initial biopsy/ surgery or radiographically suspected meningioma. Tumor volume was determined by the largest diameter in the anterior-posterior (x), superior-inferior (y), and transverse (z) dimensions using the formula for nonspherical tumor volume $=[(\pi / 6) \cdot \mathrm{x} \cdot \mathrm{y} \cdot \mathrm{z}]$. Tumor location was divided into 6 subsites: 1) parasagittal/falx cerebri; 2) convexity; 3) tentorium; 4) anterior fossa; 5) middle fossa; or 6) posterior fossa. The MIB-1 index was available for reviewing 145 of 148 cases. The presence of atypical features was determined by pathology slide review of the initial biopsy or surgical specimens.

Follow-up was calculated from the date of the initial pathological diagnosis until the last follow-up. Date of $P / R$ was defined as the date of radiological evidence of $\mathrm{P} / \mathrm{R}$ by MRI and confirmed by clinical review. A history of cranial RT and neurofibromatosis type 2(NF2) was recorded.

Extent of resection by Simpson grade was determined by review of the operative notes, imaging studies, and best clinical judgment in circumstances where it was not explicitly stated. RT information was gathered by technique (fractionated external-beam RT vs stereotactic radiosurgery) and type (photon vs proton).

\section{Statistical Analysis}

The Fisher exact test was used to compare categorical variables. Time to progression or recurrence was analyzed using univariate and multivariate Cox proportional hazards modeling with and without interaction terms. The actuarial data are presented using Kaplan-Meier plots. Cumulative incidence curves were compared using the log-rank test. The predictive power of the proposed risk of the progression model was assessed using Harrell's C concordance statistics. All p values were 2-tailed.

\section{Results}

\section{Baseline Characteristics}

The characteristics of the 148 benign meningioma patients who underwent treatment at our institution between 2002 and 2012 are summarized in Table 1. The tumors of 77 patients had atypical features, and those of 71 did not have atypical features. There were no statistical differences between cohorts by sex, median age, Karnofsky Performance Scale score, tumor location, pretreatment tumor volume, or history of NF2. Six patients had a history of cranial irradiation, all of whom had benign meningioma with atypical features $(\mathrm{p}=0.03)$.

The median follow-up was 40.8 months for patients with atypia and 34.7 months for patients without atypia $(\mathrm{p}=0.2)$. Thirty patients (20.3\%) had P/R during the duration of the 
TABLE 1. Baseline disease and treatment characteristics $(n=148)^{*}$

\begin{tabular}{|c|c|c|c|}
\hline \multirow[b]{2}{*}{ Characteristics } & \multicolumn{2}{|c|}{ Meningioma } & \multirow[b]{2}{*}{ p Value } \\
\hline & w/ Atypical Features & w/o Atypical Features & \\
\hline \multicolumn{4}{|l|}{ Baseline characteristics } \\
\hline Total no. of patients & 77 & 71 & \\
\hline Sex & & & 0.8 \\
\hline Female & $60(78)$ & $57(80)$ & \\
\hline Male & $17(22)$ & $14(20)$ & \\
\hline Age, yrs & & & 0.6 \\
\hline Median & 54 & 53 & \\
\hline Range & $13-88$ & $18-83$ & \\
\hline \multicolumn{4}{|l|}{ Karnofsky Performance Scale score } \\
\hline Median & 80 & 80 & 0.9 \\
\hline Range & $60-100$ & $60-90$ & \\
\hline Location/subsite of lesion & & & 0.1 \\
\hline Parasagittal/falx & $20(26)$ & $8(11)$ & \\
\hline Convexity & $24(31)$ & $17(24)$ & \\
\hline Tentorium & $1(1)$ & $2(3)$ & \\
\hline Anterior fossa & $6(8)$ & $9(13)$ & \\
\hline Middle fossa & $15(20)$ & $22(31)$ & \\
\hline Posterior fossa & $11(14)$ & $13(18)$ & \\
\hline Tumor volume & 66 & 71 & \\
\hline Median, $\mathrm{cm}^{3}$ & 10.1 & 8.3 & 0.7 \\
\hline Range, $\mathrm{cm}^{3}$ & $0.3-87.0$ & $0.2-75.6$ & \\
\hline Prior cranial RT & $6(8)$ & $0(0)$ & 0.03 \\
\hline History of NF2 & $3(4)$ & $3(4)$ & 1.0 \\
\hline Median follow-up (mos) & 40.8 & 34.7 & 0.2 \\
\hline Tumor progression/recurrence & $22(29)$ & $8(11)$ & 0.01 \\
\hline Median time diagnosis to P/R (mos) & 26.4 & 25.6 & 0.9 \\
\hline Median time treatment to P/R (mos) & 24.4 & 22.4 & 0.7 \\
\hline \multicolumn{4}{|l|}{ MIB-1 index } \\
\hline Available for review & $74(96)$ & $71(100)$ & \\
\hline Median MIB-1 & $4.2 \%$ & $1.9 \%$ & $<0.001$ \\
\hline MIB-1 $\geq 3 \%$ & $49(66)$ & $13(18)$ & $<0.001$ \\
\hline \multicolumn{4}{|l|}{ Atypical features } \\
\hline Increased cellularity & $44(57)$ & & \\
\hline Sheeting & $34(44)$ & & \\
\hline High N:C ratio & $3(4)$ & & \\
\hline Necrosis & $8(10)$ & & \\
\hline Prominent nucleoli & $34(44)$ & & \\
\hline \multicolumn{4}{|l|}{ Treatment characteristics } \\
\hline Primary management & & & 0.3 \\
\hline Observation & $20(26)$ & $12(17)$ & \\
\hline Surgery & $53(69)$ & $57(80)$ & \\
\hline Surgery + adjuvant RT & $4(5)$ & $2(3)$ & \\
\hline Definitive RT & $0(0)$ & $0(0)$ & \\
\hline Initial therapeutic intervention & & & 0.7 \\
\hline Surgery & $70(91)$ & $67(94)$ & \\
\hline Surgery + adjuvant RT & $6(8)$ & $3(4)$ & \\
\hline Definitive RT & $1(1)$ & $1(2)$ & \\
\hline
\end{tabular}


TABLE 1. Baseline disease and treatment characteristics $(n=148)^{*}$ (continued)

\begin{tabular}{|c|c|c|c|}
\hline \multirow[b]{2}{*}{ Characteristics } & \multicolumn{2}{|c|}{ Meningioma } & \multirow[b]{2}{*}{$\mathrm{p}$ Value } \\
\hline & w/ Atypical Features & w/o Atypical Features & \\
\hline \multicolumn{4}{|c|}{ Treatment characteristics (continued) } \\
\hline Simpson Grade resection & & & 0.6 \\
\hline Simpson Grade I & $29(38)$ & $34(48)$ & \\
\hline Simpson Grade II & $10(13)$ & $6(9)$ & \\
\hline Simpson Grade III & $3(3)$ & $2(3)$ & \\
\hline Simpson Grade IV & $35(46)$ & $28(40)$ & \\
\hline Radiotherapy characteristics & 7 & 4 & 1.0 \\
\hline \multicolumn{4}{|l|}{ Fractionated EBRT } \\
\hline Photon & 0 & 0 & \\
\hline Proton & 4 & 3 & \\
\hline \multicolumn{4}{|l|}{ SRS } \\
\hline Photon & 0 & 0 & \\
\hline Proton & 3 & 1 & \\
\hline
\end{tabular}

follow-up. The median times from diagnosis to $\mathrm{P} / \mathrm{R}$ were 26.4 months and 25.6 months for patients with and without atypia, respectively $(p=0.9)$. The median times from initial therapeutic intervention to $\mathrm{P} / \mathrm{R}$ were 24.4 and 22.4 months for patients with and without atypical features $(\mathrm{p}=$ $0.7)$. The MIB-1 index was significantly higher in the atypia cohort (median $4.2 \%$ vs $1.9 \%$; $p<0.001$ ). The proportion of patients with MIB- $1 \geq 3 \%$ was significantly higher in the atypical features group $(66 \%$ vs $18 \%$; $p<0.001)$. The distribution of the observed features of atypia was as follows: increased cellularity $(n=44 ; 57 \%)$; sheeting $(n=34 ; 44 \%)$; prominent nucleoli $(\mathrm{n}=34 ; 44 \%)$; necrosis $(\mathrm{n}=8 ; 10 \%)$; and high $\mathrm{N}: \mathrm{C}$ ratio $(\mathrm{n}=3 ; 4 \%)$.

\section{Treatment Characteristics}

Treatment selection by primary management and initial therapeutic intervention were well-balanced between cohorts $(p=0.3$ and $p=0.7$, respectively; Table 1). Whereas primary management included the choice of active surveillance, initial therapeutic intervention was defined as either or both surgery and RT. With regards to primary management, $26 \%$ of patients with atypia and $17 \%$ of patients without atypia were initially observed. Surgery alone was the most commonly selected primary management, with $69 \%$ of all patients with atypical features and $80 \%$ of all patients without atypical features undergoing this intervention. When analyzed by the initial therapeutic intervention, the treatment trends remained similar: $91 \%$ and $94 \%$ of patients with and without atypical features underwent surgery (upfront or after initial observation), respectively. The distribution of Simpson Grade I-IV resection was not statistically different ( $\mathrm{p}=$ $0.6)$.

Eleven patients underwent RT as the definitive or adjuvant treatment. Of 7 patients with atypical features treated with RT, 4 patients were treated with fractionated external-beam proton RT and 3 patients were treated with proton-based stereotactic radiosurgery. Among patients lacking atypical features, 3 patients underwent fractionated external-beam proton RT and 1 patient underwent adjuvant proton stereotactic radiosurgery.

\section{Comparison of Patients With and Without P/R}

Benign meningioma patients with $P / R$ were significantly more likely to harbor any atypical feature than patients without $P / R(p=0.01$; Table 2$)$. The distribution of the MIB-1 index percentage ( $\mathrm{p}=0.01)$ and MIB-1 $\geq 3 \%$ $(\mathrm{p}=0.007)$ were also significantly higher among patients with $\mathrm{P} / \mathrm{R}$. There was a range in frequency for each atypical feature, but patients with $\mathrm{P} / \mathrm{R}$ were more likely to have necrosis $(\mathrm{p}=0.009)$ and prominent nucleoli $(\mathrm{p}=0.001)$ than patients without tumor $\mathrm{P} / \mathrm{R}$.

There were no differences in primary management or initial therapeutic intervention between patients with and without $\mathrm{P} / \mathrm{R}$. All patients with $\mathrm{P} / \mathrm{R}$ and $91 \%$ of patients without $\mathrm{P} / \mathrm{R}$ underwent surgery as the primary therapeutic intervention. Regarding the extent of resection, there was a significant difference between cohorts $(\mathrm{p}<0.001)$, as only 1 of $30(3 \%)$ patients with P/R underwent Simpson Grade I resection compared with 62 of 118 (53\%) patients without P/R. Thus, a substantial proportion of patients with $\mathrm{P} / \mathrm{R}$ initially underwent incomplete resection. There were too few patients to assess whether RT was able to modify $\mathrm{P} / \mathrm{R}$ risk. However, 0 of 11 patients treated with RT experienced $\mathrm{P} / \mathrm{R}$.

\section{Atypical Features}

The prognostic significance of atypical features in benign meningiomas for the incidence of $P / R$ is illustrated in Fig. 1. Patients with atypical features had a significantly increased risk of $\mathrm{P} / \mathrm{R}$ compared with patients without atypia ( $\mathrm{p}=0.03$ on the log-rank test). The 1-year actuarial rate of $\mathrm{P} / \mathrm{R}$ was $9.6 \%$ (95\% confidence interval [CI] 4.7-19.1) and $1.4 \%$ (95\% CI 0.2-9.7) for tumors with and without 
TABLE 2. Disease and treatment characteristics for patients with $(n=30)$ and without $(n=118)$ progression/recurrence

\begin{tabular}{|c|c|c|c|}
\hline \multirow[b]{2}{*}{ Baseline Characteristics } & \multicolumn{2}{|c|}{ No. of Patients (\%) } & \multirow[b]{2}{*}{$p$ Value } \\
\hline & $\mathrm{P} / \mathrm{R}$ & No P/R & \\
\hline No. of patients & 30 & 118 & \\
\hline \multicolumn{4}{|l|}{ MIB-1 index } \\
\hline Median MIB-1 & $4.3 \%$ & $2.5 \%$ & 0.01 \\
\hline MIB-1 $>3 \%$ & $19(66)$ & $43(37)$ & 0.007 \\
\hline Atypical features $(n=77)$ & $22(73)$ & $55(47)$ & 0.01 \\
\hline Increased cellularity & $9(30)$ & $35(30)$ & 1.0 \\
\hline Sheeting & $8(27)$ & $26(22)$ & 0.6 \\
\hline High $\mathrm{N}: \mathrm{C}$ ratio & $0(0)$ & $3(2)$ & 1.0 \\
\hline Necrosis & $5(17)$ & $3(2)$ & 0.009 \\
\hline Prominent nucleoli & $14(47)$ & $20(17)$ & 0.001 \\
\hline \multicolumn{4}{|l|}{ Treatment characteristics } \\
\hline Primary management & & & 0.4 \\
\hline Observation & $7(23)$ & $25(21)$ & \\
\hline Surgery & $23(77)$ & $87(74)$ & \\
\hline Surgery + adjuvant RT & 0 & $6(5)$ & \\
\hline Definitive RT & 0 & $0(0)$ & \\
\hline Initial therapeutic intervention & & & 0.2 \\
\hline Surgery & $30(100)$ & $107(91)$ & \\
\hline Surgery + adjuvant RT & 0 & $9(8)$ & \\
\hline Definitive RT & 0 & $2(2)$ & \\
\hline Simpson Grade & & & $<0.001$ \\
\hline Simpson Grade I & $1(3)$ & $62(53)$ & \\
\hline Simpson Grade II & $2(7)$ & $14(12)$ & \\
\hline Simpson Grade III & $2(7)$ & $2(2)$ & \\
\hline Simpson Grade IV & $25(83)$ & $38(33)$ & \\
\hline
\end{tabular}

atypical features, respectively. The 5-year actuarial rate of $\mathrm{P} / \mathrm{R}$ was $30.3 \%$ (95\% CI 19.0-46.1) and $13.8 \%$ (95\% CI 6.6-28.1) for tumors with and without atypical features, respectively.

On the univariate analysis (Table 3), the presence of any atypical feature (1-2 vs 0 features) significantly increased the risk of $P / R$ (hazard ratio $[H R]=2.4 ; p=0.04$ ). The presence of necrosis $(\mathrm{p}=0.004)$ and prominent nucleoli $(\mathrm{p}=0.02)$ were also associated with an increased risk of $\mathrm{P} / \mathrm{R}$. Commonly observed features of increased cellularity and sheeting, which were present in $57 \%$ and $44 \%$ of all patients with atypia, respectively, were not associated with increased $\mathrm{P} / \mathrm{R}$ risk on the univariate analysis.

\section{MIB-1 Index}

Both the median MIB-1 index and proportion of tumors with MIB-1 index $\geq 3 \%$ were significantly higher in the cohort with atypical features. The risk of $\mathrm{P} / \mathrm{R}$ for patients with a MIB-1 index $\geq 3 \%$ was significantly higher $(\mathrm{HR}=2.4 ; \mathrm{p}=0.03)$. The actuarial incidence of $\mathrm{P} / \mathrm{R}$ for tumors with MIB-1 index $<3 \%$ and $\geq 3 \%$ was $2.4 \%(95 \%$ CI 0.6-9.3) versus $10.6 \%$ (95\% CI 4.9-22.1) at 1-year and $16.3 \%$ (95\% CI 8.5-30.0) versus $31.2 \%$ (95\% CI 18.6-49.1) at 5 years, respectively.

\section{Extent of Resection}

Patients who underwent Simpson Grade II-IV resection were at significantly increased risk of $\mathrm{P} / \mathrm{R}(\mathrm{HR}=20.5$; $\mathrm{p}=0.003$ ) compared with their counterparts undergoing Simpson Grade I resection (Table 3 and Fig. 2). The actuarial incidence of P/R for Simpson Grade I and Simpson Grade II-IV resection was $0 \%$ versus $10.2 \%$ (95\% CI 5.2$19.3)$ at 1 year and $1.7 \%(95 \%$ CI $0.2-11.2)$ versus $36.4 \%$ (95\% CI 25.0-50.9) at 5 years, respectively. The crude rate of P/R by Simpson resection was $1.6 \%$ (1 of 63 patients) for Grade I and 34.9\% for Grade II-IV resection (29 of 83 patients). Analysis by the individual Simpson grade was not feasible with the limited number of Simpson Grade II and III resections, but the crude rates of P/R by Simpson grade are included in Table 4 . These data suggest that failure to achieve Simpson Grade I resection may be an important risk factor for $\mathrm{P} / \mathrm{R}$.

\section{Stratification of Benign Meningiomas Into P/R Risk Groups}

We developed a P/R risk model based on the presence of any atypical features and extent of resection. As previously discussed, the risk of $\mathrm{P} / \mathrm{R}$ was exceedingly low (crude rate of $1.6 \%$ ) for patients undergoing Simpson Grade I resection. Furthermore, in the setting of Simpson Grade I resection, the presence or absence of atypical features did not significantly influence $\mathrm{P} / \mathrm{R}$ risk. However, among patients who underwent Simpson Grade II-IV resection, the presence of atypical features did appear to impact the risk of $\mathrm{P} / \mathrm{R}$. Therefore, we defined the following risk cohorts: 1) low-risk subset defined as patients who underwent Simpson Grade I resection regardless of the presence of atypia; 2) intermediate-risk subset defined as patients who underwent Simpson Grade II-IV resection without atypical features; and 3) high-risk subset defined as patients who underwent Simpson Grade II-IV resection with atypical features. In the multivariate analysis (Table 3) using Simpson Grade I resection as a reference (low risk), patients with Simpson Grade II-IV resection without atypical features (intermediate risk) had a significantly increased risk of $\mathrm{P} / \mathrm{R}(\mathrm{HR}=16.0 ; \mathrm{p}=0.009)$, and patients with Simpson Grade II-IV resection with atypical features (high risk) had a further increased risk of $P / R$ $(\mathrm{HR}=33.5 ; \mathrm{p}=0.001)$. The cumulative incidence of $\mathrm{P} / \mathrm{R}$ for the 3 risk groups is shown in Fig. 3 .

To further explore the importance of the atypical features in relation to both Simpson grade and MIB-1 index, a multivariate Cox analysis (Table 5) was performed and demonstrated that atypical features are significantly associated with $\mathrm{P} / \mathrm{R}(\mathrm{HR} 8.7 ; \mathrm{p}=0.01)$ when adjusted for MIB1 index and Simpson Grade II/III/IV.

\section{Discussion}

To the best of our knowledge, this is the first contemporary study examining the prognostic significance of atypical features among benign meningiomas. In our series, patients with benign meningiomas possessing atypical features were found to have a significant risk of $P / R$ in comparison with their benign counterparts lacking atypical features. This raises questions as to whether benign 


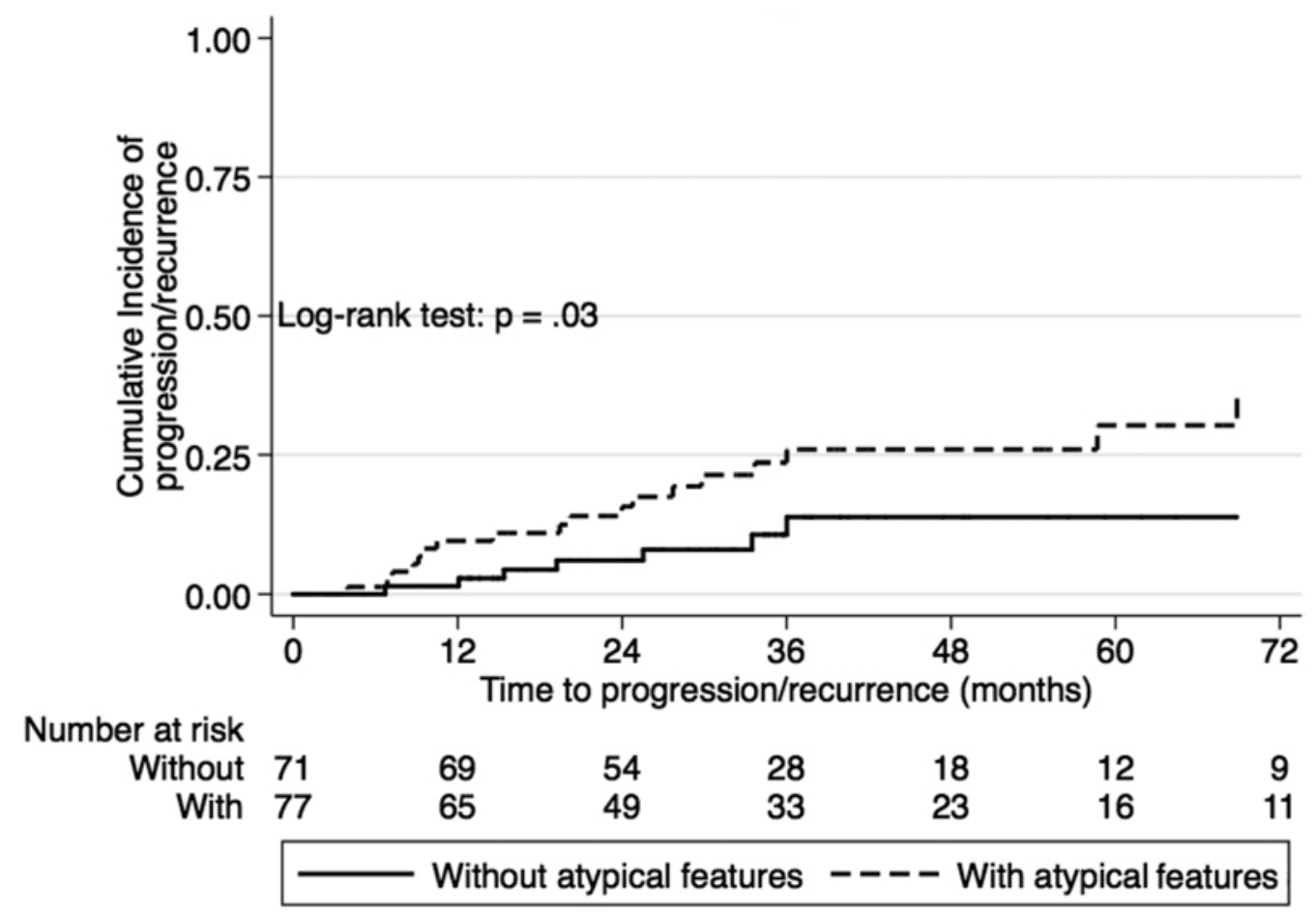

FIG. 1. Cumulative incidence of $P / R$ by the presence of atypical features.

meningiomas with atypical features represent an entity on a continuous spectrum of disease between benign tumors lacking atypia and higher grade meningiomas.

Our findings support that the presence of any atypical

TABLE 3. Univariate and multivariate Cox analysis of the patient, histopathologic and treatment-related factors for time to P/R

\begin{tabular}{|c|c|c|}
\hline Variable & $\operatorname{HR}(95 \% \mathrm{Cl})$ & $\mathrm{p}$ Value \\
\hline \multicolumn{3}{|l|}{ Univariate analysis } \\
\hline Location/subsite & & $0.9^{*}$ \\
\hline Tumor volume, $\mathrm{cm}^{3}$ & $0.98(0.95-1.01)$ & 0.2 \\
\hline MIB-1 index $>3 \%$ vs $<3 \%$ & $2.4(1.1-5.2)$ & 0.03 \\
\hline \multicolumn{3}{|l|}{ Presence of atypical features } \\
\hline Increased cellularity & $0.8(0.4-1.9)$ & 0.7 \\
\hline Sheeting & $1.7(0.7-4.0)$ & 0.2 \\
\hline Prominent nucleoli & $2.4(1.2-5.2)$ & 0.02 \\
\hline Necrosis & $4.2(1.6-11.3)$ & 0.004 \\
\hline High N:C ratio & & $1.0^{*}$ \\
\hline $\begin{array}{l}\text { Any atypical feature (1-2) vs } \\
\text { none }(0)\end{array}$ & $2.4(1.04-5.4)$ & 0.04 \\
\hline \multicolumn{3}{|l|}{ Initial therapeutic intervention } \\
\hline Simpson Grade II-IV vs Grade I & $20.5(2.8-150.8)$ & 0.003 \\
\hline Adjuvant or definitive RT vs none & $4.2(1.4-12.7)$ & 0.01 \\
\hline \multicolumn{3}{|l|}{ Multivariate analysis } \\
\hline \multicolumn{3}{|l|}{ Grade I as a reference } \\
\hline Grade II/III/IV w/o atypical feature & $16.0(2.0-129.0)$ & 0.009 \\
\hline Grade II/III/IV w/ atypical feature & $33.5(4.5-251.6)$ & 0.001 \\
\hline
\end{tabular}

feature and MIB-1 index $\geq 3 \%$ are prognostic for an increased risk of $\mathrm{P} / \mathrm{R}$. Interestingly, on the univariate analysis, the specific atypical features of necrosis and prominent nucleoli were significantly associated with the risk of P/R. Necrosis was not frequently observed and was present in only 8 patients (5\% of all patients). However, 5 of 8 patients (63\%) with necrosis experienced P/R. On the other hand, the presence of prominent nucleoli was a more commonly observed atypical feature. Of the 34 patients with prominent nucleoli, 14 (41\%) experienced P/R. Further correlative analysis and prospective research is needed to clarify a direct link between specific atypical features and aggressive tumor biology. Similarly, other groups have explored the use of histopathologic parameters to develop a prognostic model for the risk of recurrence of meningiomas. Ho et al. assessed 13 histological parameters and determined that a model incorporating the presence of mitoses $\geq 1.5 / \mathrm{mm}^{2}$, loss of architecture, and necrosis was the best indicator of risk of recurrence. Additionally, the MIB-1 index was a powerful prognosticator of recurrence, and $97 \%$ of tumors with a MIB-1 index $>10 \%$ recurred within 10 years. ${ }^{10}$ These findings suggest that both the MIB-1 index and atypical features warrant inclusion in the pathology reports of benign meningiomas.

Another important finding from our analyses was the association between the extent of surgical resection and risk of $\mathrm{P} / \mathrm{R}$. We observed that a lesser extent of resection was associated with an increased risk of $\mathrm{P} / \mathrm{R}$ among all benign meningioma patients, independent of the presence or absence of atypical features. Specifically, failure to achieve a Simpson Grade I resection correlated with an increased risk of $\mathrm{P} / \mathrm{R}$. However, the risk of $\mathrm{P} / \mathrm{R}$ could not be adequately assessed for all individual grades of resection. 


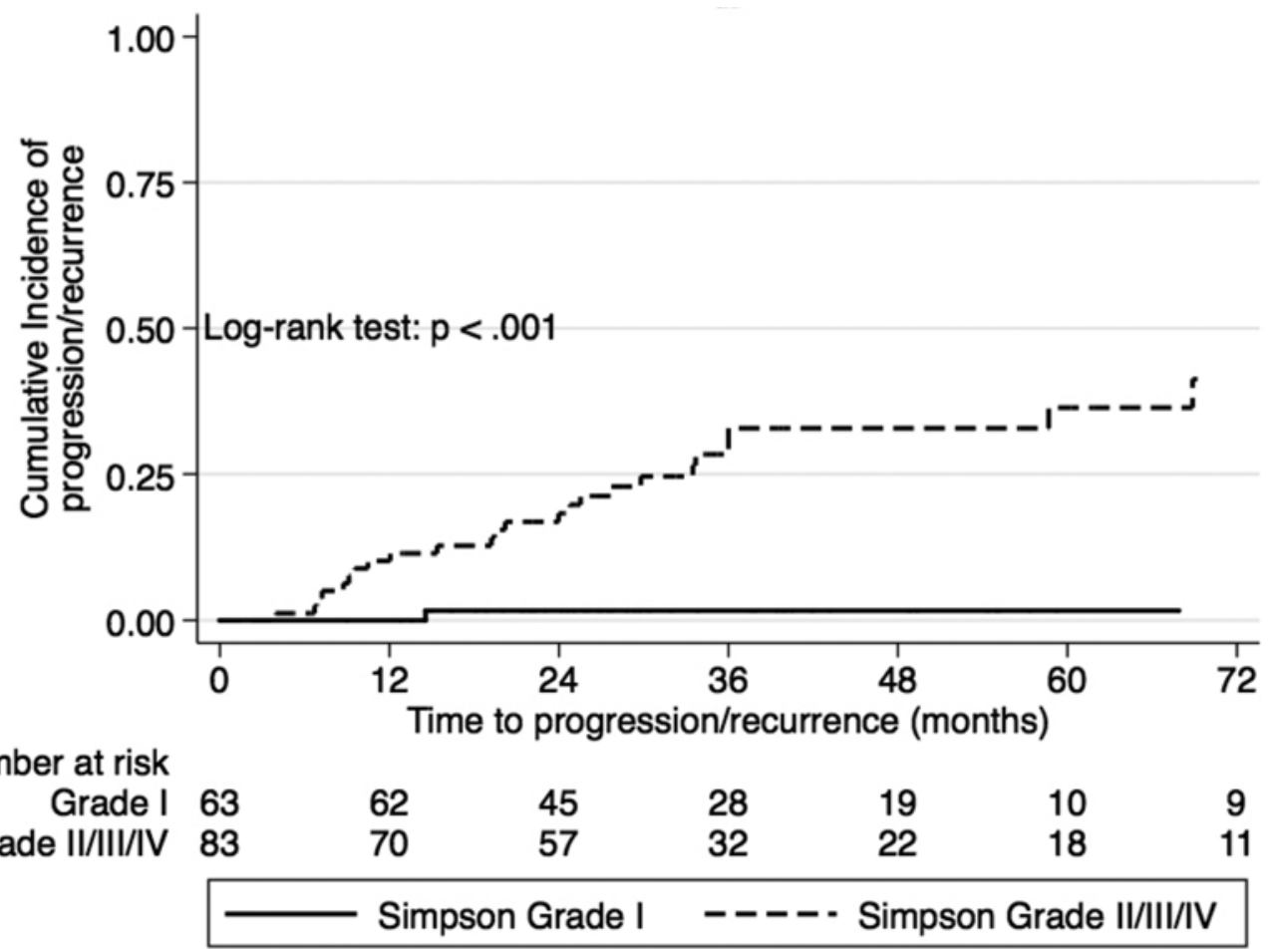

FIG. 2. Cumulative incidence of $P / R$ by the extent of resection.

Other groups have argued that $\mathrm{P} / \mathrm{R}$-free survival is similar among benign meningiomas undergoing Simpson Grade I or II resection..$^{27}$

The management of WHO Grade I meningiomas after incomplete surgery, such as the appropriate indications for adjuvant RT, remains debatable. Due to the suboptimal evidence and evolving diagnostic criteria, a high degree of interinstitutional variability exists with regards to therapeutic decision making. ${ }^{25}$ In an attempt to clarify this issue, we found that atypical features (presence or absence) and the degree of Simpson resection (Grade I vs II-IV) could successfully stratify patients with benign meningiomas into groups at low, intermediate, and high risk of P/R. Given the increased propensity for $\mathrm{P} / \mathrm{R}$ among the subset of benign tumors with atypical features, more frequent follow-up and/or adjuvant RT should be considered, particularly in the setting of failure to achieve Simpson Grade I resection, similar to the common practice with atypical meningiomas.

Several retrospective series have demonstrated the efficacy of adjuvant RT for WHO Grade II-III meningiomas. ${ }^{1,4,7,8,11,17}$ The role for adjuvant RT among benign meningiomas remains poorly defined due to a lack of prospective randomized data, which adds to the importance to our findings..$^{28}$ Unfortunately, European Organisation for Research and Treatment of Cancer (EORTC) trial 26021-22021 - a Phase III study that randomized patients with WHO Grade I meningiomas after incomplete resection to observation versus adjuvant conventional RT or radiosurgery groups-was closed early due to the poor accrual of patients. The results of this study would have provided useful information to define the treatment paradigm of benign meningiomas. At present, only retrospective series exist supporting the role of adjuvant RT. Condra et al. ${ }^{6}$ reviewed a series of 262 benign meningioma patients and found that local control and cause-specific survival among patients undergoing total excision (Simpson Grade I-III) or subtotal excision (Simpson Grade IV) with adjuvant RT were comparable to one another, and both were superior to subtotal excision alone. Interestingly, the presence of atypical features (defined as increased cellularity, pleomorphism, and mitoses without evidence of brain invasion) was a significant poor prognostic factor on the multivariate analysis. Additionally, a retrospective analysis of 92 WHO Grade I meningioma patients who underwent STR reported that adjuvant RT had significantly improved 5-year progression-free survival compared with STR alone (91\% vs 38\%), although no overall survival benefit was observed. ${ }^{26}$ The concern that upfront adjuvant treatment exposes patients to the potential treatment-related side effects and long-term toxicities associated with RT makes the identification of the subset of patients at highest risk of $\mathrm{P} / \mathrm{R}$ of critical importance. ${ }^{30}$

As a more comprehensive understanding of meningio-

TABLE 4. Crude rate of P/R by Simpson Grade

\begin{tabular}{crcc}
\hline Simpson Grade & P/R & No P/R & Crude Rate of P/R \\
\hline Grade I & 1 & 62 & $1.6 \%$ \\
\hline Grade II & 2 & 14 & $12.5 \%$ \\
\hline Grade III & 2 & 2 & $50 \%$ \\
\hline Grade IV & 25 & 38 & $39.7 \%$ \\
\hline
\end{tabular}




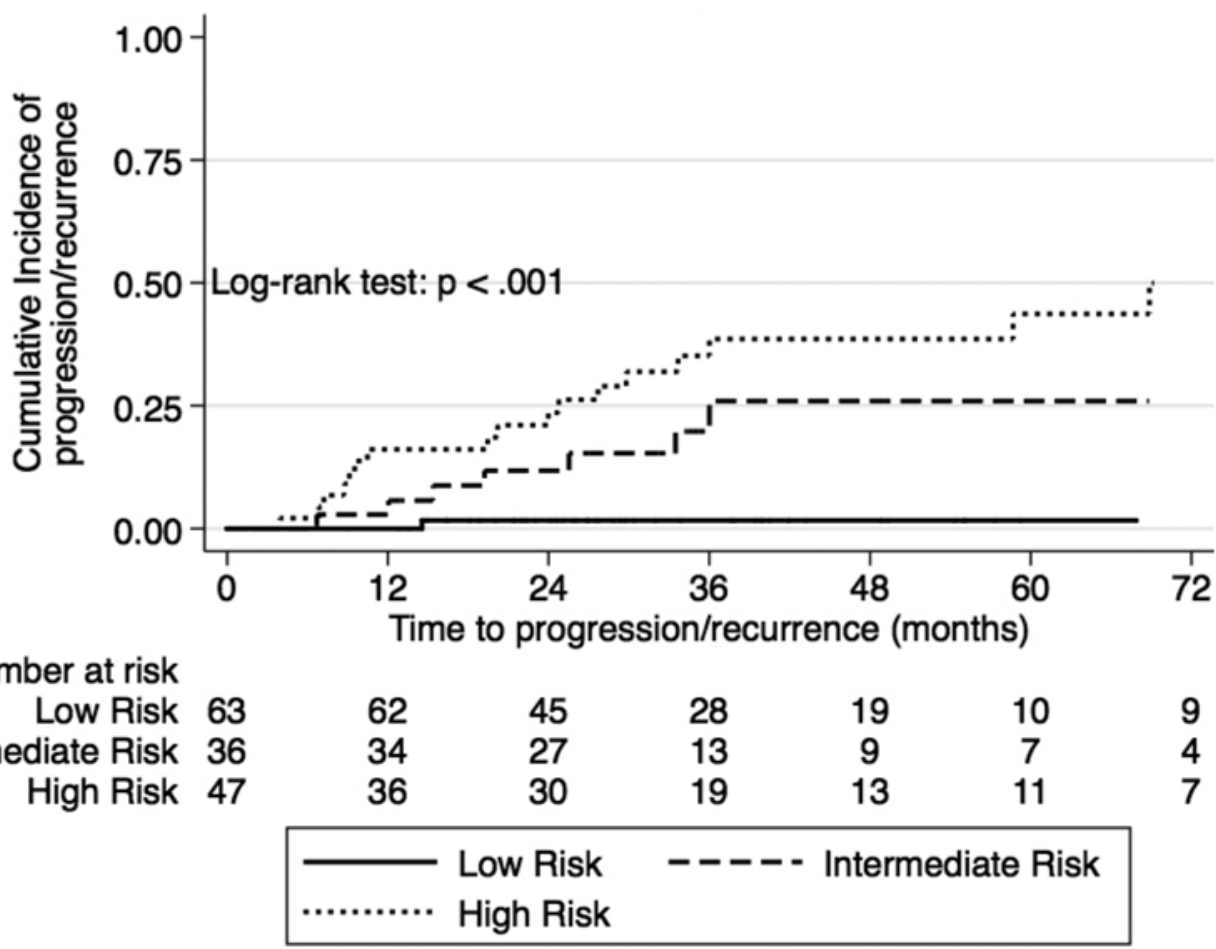

FIG. 3. Cumulative incidence of $P / R$ by the extent of resection and presence of atypical features. Low risk represents Grade I with or without atypical features. Intermediate risk represents Grade II/III/IV without atypical features. High risk represents Grade II/III/ IV with atypical features.

ma biology is gained, a more sophisticated classification system that integrates histopathological criteria, molecular/genetic analysis, extent of surgical resection, imaging findings, and patient/tumor characteristics could help to prognosticate patients and direct therapeutic decision making. ${ }^{3,20}$ Taken all together, an individualized approach to clinical decision making should be applied that factors in patient-specific, tumor-intrinsic, and treatment-related factors in order to achieve optimal outcomes for patients with benign meningiomas. We acknowledge that the limitations of our study are the retrospective nature of our analysis at a single institution, a limited duration of patient follow-up, limited number of $\mathrm{P} / \mathrm{R}$ events, and lack of statistical power to further assess the impact of both surgery and/or RT.

\section{Conclusions}

Our work suggests that patients with benign meningiomas with atypical features who do not achieve Simp-

TABLE 5. Multivariate Cox analysis of Simpson Grade, atypical features, and MIB-1 index for time to P/R

\begin{tabular}{lcc}
\hline \multicolumn{1}{c}{ Multivariate Analysis } & HR $(95 \% \mathrm{Cl})$ & p Value \\
\hline Simpson Grade II-IV vs I & $20.1(2.7-149.4)$ & 0.003 \\
\hline $\begin{array}{l}\text { Presence of atypical features vs } \\
\text { none }\end{array}$ & $8.7(1.6-47.5)$ & 0.01 \\
\hline MIB-1 index $>3 \%$ vs $<3 \%$ & $1.6(1.0-2.3)$ & 0.03 \\
\hline $\begin{array}{l}\text { Interaction of MIB-1 index w/ pres- } \\
\text { ence of atypical features }\end{array}$ & $0.62(0.40-0.94)$ & 0.03 \\
\hline
\end{tabular}

son Grade I resection are at significantly increased risk of $\mathrm{P} / \mathrm{R}$ after initial surgery. Our findings also corroborate the notion that benign meningiomas with MIB-1 index $\geq 3 \%$ have an increased propensity for P/R. Finally, we developed a novel tool to stratify benign meningiomas into risk groups based on the presence of atypia and extent of resection. Patients with any of the aforementioned risk factors, particularly patients with Simpson Grade II-IV with atypical features, may benefit from closer surveillance and consideration of additional therapies, including further surgery and/or adjuvant RT.

\section{References}

1. Aghi MK, Carter BS, Cosgrove GR, Ojemann RG, AminHanjani S, Martuza RL, et al: Long-term recurrence rates of atypical meningiomas after gross total resection with or without postoperative adjuvant radiation. Neurosurgery 64:56-60, 2009

2. Backer-Grøndahl T, Moen BH, Torp SH: The histopathological spectrum of human meningiomas. Int J Clin Exp Pathol 5:231-242, 2012

3. Barbera S, San Miguel T, Gil-Benso R, Muñoz-Hidalgo L, Roldan P, Gonzalez-Darder J, et al: Genetic changes with prognostic value in histologically benign meningiomas. Clin Neuropathol 32:311-317, 2013

4. Boskos C, Feuvret L, Noel G, Habrand JL, Pommier P, Alapetite $\mathrm{C}$, et al: Combined proton and photon conformal radiotherapy for intracranial atypical and malignant meningioma. Int J Radiat Oncol Biol Phys 75:399-406, 2009

5. Combs SE, Schulz-Ertner D, Debus J, von Deimling A, Hartmann C: Improved correlation of the neuropathologic classification according to adapted world health organization classification and outcome after radiotherapy in patients with 
atypical and anaplastic meningiomas. Int J Radiat Oncol Biol Phys 81:1415-1421, 2011

6. Condra KS, Buatti JM, Mendenhall WM, Friedman WA, Marcus RB Jr, Rhoton AL: Benign meningiomas: primary treatment selection affects survival. Int J Radiat Oncol Biol Phys 39:427-436, 1997

7. Dziuk TW, Woo S, Butler EB, Thornby J, Grossman R, Dennis WS, et al: Malignant meningioma: an indication for initial aggressive surgery and adjuvant radiotherapy. J Neurooncol 37:177-188, 1998

8. Goldsmith BJ, Wara WM, Wilson CB, Larson DA: Postoperative irradiation for subtotally resected meningiomas. A retrospective analysis of 140 patients treated from 1967 to 1990. J Neurosurg 80:195-201, 1994

9. Goyal LK, Suh JH, Mohan DS, Prayson RA, Lee J, Barnett GH: Local control and overall survival in atypical meningioma: a retrospective study. Int J Radiat Oncol Biol Phys 46:57-61, 2000

10. Ho DM, Hsu CY, Ting LT, Chiang H: Histopathology and MIB-1 labeling index predicted recurrence of meningiomas: a proposal of diagnostic criteria for patients with atypical meningioma. Cancer 94:1538-1547, 2002

11. Hug EB, Devries A, Thornton AF, Munzenride JE, Pardo FS, Hedley-Whyte ET, et al: Management of atypical and malignant meningiomas: role of high-dose, 3D-conformal radiation therapy. J Neurooncol 48:151-160, 2000

12. Jääskeläinen J, Haltia M, Servo A: Atypical and anaplastic meningiomas: radiology, surgery, radiotherapy, and outcome. Surg Neurol 25:233-242, 1986

13. Ko KW, Nam DH, Kong DS, Lee JI, Park K, Kim JH: Relationship between malignant subtypes of meningioma and clinical outcome. J Clin Neurosci 14:747-753, 2007

14. Louis DN, Scheitauer BW, Budka H, Von Deimling A, Kepes JJ: Meningiomas, in Kleiues P, Cavenee WK (eds): World Health Organization Classification of Tumours. Pathology and Genetics. Tumors of the Nervous System. Lyon, France: IARC Press, 2000, pp 176-184

15. Louis DN, Ohgaki H, Wiestler OD, Cavenee WK, Burger PC, Jouvet A, et al: The 2007 WHO classification of tumours of the central nervous system. Acta Neuropathol 114:97-109, 2007

16. Matsuno A, Fujimaki T, Sasaki T, Nagashima T, Ide T, Asai A, et al: Clinical and histopathological analysis of proliferative potentials of recurrent and non-recurrent meningiomas. Acta Neuropathol 91:504-510, 1996

17. Modha A, Gutin PH: Diagnosis and treatment of atypical and anaplastic meningiomas: a review. Neurosurgery 57:538550, 2005

18. Ohta M, Iwaki T, Kitamoto T, Takeshita I, Tateishi J, Fukui M: MIB1 staining index and scoring of histologic features in meningioma. Indicators for the prediction of biologic potential and postoperative management. Cancer 74:3176-3189, 1994

19. Ostrom QT, Gittleman H, Farah P, Ondracek A, Chen Y, Wolinsky Y, et al: CBTRUS statistical report: Primary brain and central nervous system tumors diagnosed in the United States in 2006-2010. Neuro Oncol 15 (Suppl 2):ii1-ii56, 2013

20. Oya S, Kawai K, Nakatomi H, Saito N: Significance of Simpson grading system in modern meningioma surgery: integration of the grade with MIB-1 labeling index as a key to predict the recurrence of WHO Grade I meningiomas. J Neurosurg 117:121-128, 2012

21. Palma L, Celli P, Franco C, Cervoni L, Cantore G: Longterm prognosis for atypical and malignant meningiomas: a study of 71 surgical cases. J Neurosurg 86:793-800, 1997

22. Pearson BE, Markert JM, Fisher WS, Guthrie BL, Fiveash JB, Palmer CA, et al: Hitting a moving target: evolution of a treatment paradigm for atypical meningiomas amid changing diagnostic criteria. Neurosurg Focus 24(5):E3, 2008
23. Rosenberg LA, Prayson RA, Lee J, Reddy C, Chao ST, Barnett GH, et al: Long-term experience with World Health Organization grade III (malignant) meningiomas at a single institution. Int J Radiat Oncol Biol Phys 74:427-432, 2009

24. Saraf S, McCarthy BJ, Villano JL: Update on meningiomas. Oncologist 16:1604-1613, 2011

25. Simon M, Boström J, Koch P, Schramm J: Interinstitutional variance of postoperative radiotherapy and follow up for meningiomas in Germany: impact of changes of the WHO classification. J Neurol Neurosurg Psychiatry 77:767-773, 2006

26. Soyuer S, Chang EL, Selek U, Shi W, Maor MH, DeMonte F: Radiotherapy after surgery for benign cerebral meningioma. Radiother Oncol 71:85-90, 2004

27. Sughrue ME, Kane AJ, Shangari G, Rutkowski MJ, McDermott MW, Berger MS, et al: The relevance of Simpson Grade I and II resection in modern neurosurgical treatment of World Health Organization Grade I meningiomas. J Neurosurg 113:1029-1035, 2010

28. Taylor BW Jr, Marcus RB Jr, Friedman WA, Ballinger WE Jr, Million RR: The meningioma controversy: postoperative radiation therapy. Int J Radiat Oncol Biol Phys 15:299-304, 1988

29. Trembath D, Miller CR, Perry A: Gray zones in brain tumor classification: evolving concepts. Adv Anat Pathol 15:287297, 2008

30. Wenkel E, Thornton AF, Finkelstein D, Adams J, Lyons S, De La Monte S, et al: Benign meningioma: partially resected, biopsied, and recurrent intracranial tumors treated with combined proton and photon radiotherapy. Int J Radiat Oncol Biol Phys 48:1363-1370, 2000

31. Whittle IR, Smith C, Navoo P, Collie D: Meningiomas. Lancet $363: 1535-1543,2004$

32. Willis J, Smith C, Ironside JW, Erridge S, Whittle IR, Everington D: The accuracy of meningioma grading: a 10-year retrospective audit. Neuropathol Appl Neurobiol 31:141149,2005

\section{Disclosure}

Dr. Shih is a writer for UpToDate and a senior editor for the International Journal of Radiation Oncology • Biology • Physics. Dr. Stemmer-Rachamimov is an editorial board member for Brain Pathology. Dr. Curry is a consultant for Stryker CMF.

\section{Author Contributions}

Conception and design: Shih, Marciscano, Stemmer-Rachamimov, Niemierko, Larvie. Acquisition of data: Shih, Marciscano, Stemmer-Rachamimov, Larvie, Curry, McGuone. Analysis and interpretation of data: all authors. Drafting the article: Shih, Marciscano, Niemierko. Critically revising the article: all authors. Reviewed submitted version of manuscript: all authors. Approved the final version of the manuscript on behalf of all authors: Shih. Statistical analysis: Niemierko. Administrative/technical/material support: Shih, Marciscano, Stemmer-Rachamimov, Larvie, Curry, Barker, Martuza, McGuone. Study supervision: Shih, Larvie.

\section{Supplemental Information \\ Previous Presentation}

A portion of this work was presented as an abstract in a poster discussion forum at the 55th Annual Meeting of the American Society of Therapeutic Radiation Oncology (ASTRO), Atlanta, Georgia, September 2013.

\section{Correspondence}

Helen A. Shih, Department of Radiation Oncology, Massachusetts General Hospital, 30 Fruit St., Boston, MA 02114. email: hshih@mgh.harvard.edu. 